Ideology, Education, and Couple's Voting Preferences in the 2016 Presidential Election

Matthew H. Goldberg

Yale University 


\begin{abstract}
One nationally representative study tested whether ideology predicted likelihood of people voting for a different candidate from their romantic partner in the 2016 United States presidential election. Extending upon recent research on informational social influence and ideological differences in values, results show that conservatives were more likely to vote for the same candidate as their partner than liberals were, but only for people with little education. This relationship reverses for people with high education such that conservatives were more likely than liberals to vote for a different candidate from their romantic partner. I discuss theoretical implications of these findings when considering the conflict between people's political views and their loyalty to close relationship partners.
\end{abstract}


Ideology, Education, and Couple's Voting Preferences in the 2016 Presidential Election

Social influence has powerful effects across a wide range of people's attitudes and behaviors (e.g., Sherif, 1936; Asch, 1955; Cialdini, Reno, \& Kallgren, 1990). This happens in part because people are fundamentally driven to share beliefs with others in order to understand their complex world and to fulfill relational needs (Hardin \& Higgins, 1996; Hardin \& Conley, 2001). Although the motivation to conform to others' beliefs is pervasive, are there ideological differences in people's need to conform?

A growing line of research suggests this answer is yes (e.g., Goldberg, van der Linden, Leiserowitz, \& Maibach, 2019). Conservatives have been shown to value loyalty and conformity more than liberals do (Caprara, Schwartz, Capanna, Vecchione, \& Barbaranelli, 2006; Graham et al., 2009), and have stronger motivations to adopt the same views as like-minded others (Jost, van der Linden, Panagopoulos, \& Hardin, 2018; Stern, West, Jost, \& Rule, 2014). This should be especially influential for highly important relationships, such as with a romantic partner, particularly because romantic partners are seen as overlapping with one's self concept (Aron, Aron, Tudor, \& Nelson, 1991). However, research is scant on the extent to which ideology predicts whether people share important beliefs with their partner. A real world and highly contentious context to investigate this question is the 2016 United States presidential election.

\section{The 2016 United States Presidential Election}

The 2016 presidential election was very divisive for the United States. The political left and right continued to polarize in their beliefs (Pew Research Center, 2016a) and have stronger negative feelings towards one another (Pew Research Center, 2016b). This poses a problem especially for romantic couples with different political leanings. Consider the following example: 
a passionate conservative named John, like most other conservatives, will be inclined to support the Republican candidate for president. If he is married to someone who supports a different candidate, it places John in a difficult situation. On one hand, he is motivated by a host of psychological and personality factors to support the Republican (i.e., more conservative) candidate (e.g., see Jost, 2017; Caprara et al., 2006). But at the same time, John is highly motivated to remain loyal to his partner and agree to support the same candidate. How does this kind of situation influence his voting behavior?

The answer appears to be due at least in part to his ability to justify his pre-existing political views. For example, Rios, Goldberg, and Totton (2018) conducted two experiments investigating factors that make people more likely to resist conformity and still express their position even if they know they have a minority opinion (i.e., most Americans disagree with the participants' position). Ordinarily, people with a minority opinion are more hesitant to express their views (e.g., Noelle-Neumann, 1993; Gearhart \& Zhang, 2015) or decide to conform (e.g., Asch, 1955). Rios and colleagues (2018) found that perceived knowledge played a critical role in resisting the social influence of being in the minority. That is, people with a minority opinion who believed they had a low ability to justify their views (i.e., low perceived knowledge) were more hesitant to express their views and less likely to choose a discussion partner with different views. People with a minority opinion who believed they had a high ability to justify their views (i.e., high perceived knowledge), however, were just as likely to express their views as people in the majority. The authors explained that these effects were driven by an informational influence process: having others disagree with you can signal to you that you are incorrect, but people resist this kind of informational social influence when they are knowledgeable enough to 
overcome it. In the current study, we use participant education as a proxy measure for knowledge (see Method section).

The current study expands upon previous research by investigating this process as a function of political ideology, and doing so in the context of a more consequential relationship than a simple minority/majority status: whether one agrees with their significant other. Most previous research has used social influence via norms (Cialdini et al., 1990) or whether most Americans agree or disagree with the respondent (Rios et al., 2018). The current study has additional theoretical implications because it extends this research to romantic partners. Additionally, the current research uses nationally representative data based on real world events (i.e., 2016 presidential election), making it more externally and ecologically valid.

Because conservatives value loyalty and conformity more than liberals do (e.g., Caprara et al., 2006), I hypothesize, compared to liberals, conservatives will be less likely to vote for a different candidate from their significant other. Importantly, however, I hypothesize an ideology $\times$ education interaction such that conservatives will be less likely than liberals to vote for a different candidate than their significant other especially when they have little education, but this relationship will be weak or non-existent for participants that are highly educated.

\section{Method}

\section{Participants}

Nationally representative data were collected via Pew Research Center between September $27^{\text {th }}$ and October $10^{\text {th }}, 2016$. These data are available for download from www.people-press.org/datasets/ under the label American Trends Panel Wave 21. In total, 4,132 participants completed the study. Because our analyses focused on voting couples, our sample was comprised of 2,476 participants (see next section for details). For all details regarding 
sampling method and demographic breakdown of the sample, see the Pew Research Center report entitled, Most Trump, Clinton Backers Say Spouses Share Their Vote Preferences (Pew Research Center, 2016c).

\section{Materials and Procedure}

Participants took part in the study approximately one month before the 2016 presidential election. They answered questions regarding their voting behavior and other activities (e.g., donations to a campaign). Of particular relevance to the current study, participants were asked who they were going to vote for and who they believed their partner was going to vote for. To gauge participants' vote preference, they were asked, "If the 2016 presidential election were being held today, would you vote for... (Donald Trump, the Republican; Hillary Clinton, the Democrat; Gary Johnston, the Libertarian Party candidate; Jill Stein, the Green Party candidate; Vote for none/Other)." To gauge participants' partner's voting preference, they were asked, "Do you happen to know who your spouse/partner is planning to vote for in the presidential election? (Donald Trump, Hillary Clinton, Other candidate, Don't know).” To create the dependent measure, we used the answers to these two questions to determine whether the participant voted for the same candidate as their partner $(0=\text { Same candidate, } 1=\text { Different candidate })^{1,2}$.

Participant ideology was rated from 1 (Very liberal) to 5 (Very conservative). Because there were no items explicitly measuring perceived or objective political knowledge, we used participants' education as a proxy, as previous research has done (e.g., van der Linden,

\footnotetext{
${ }^{1}$ Because the question asking about the participant's partner's voting preference did not specifically include Gary Johnson or Jill Stein as options, it was only possible to create this measure for participants who voted for either Hillary Clinton or Donald Trump.

2 Participants who voted themselves but chose "Don't know" for their partner's vote preference were marked as having voted for a different candidate than their partner. This is because the same theoretical arguments apply when agreement with one's partner is not certain (e.g., Noelle-Neumann, 1993). I ran the same analyses with these participants excluded and the results followed the same pattern as reported in the main text (see supplementary materials).
} 
Leiserowitz, \& Maibach, 2018; 1 = Less than high school, 2 = High school graduate, $3=$ Some college, no degree, 4 = Associate's degree, $5=$ College graduate/some postgrad, $6=$ Postgraduate). Details for all measures are available in the Pew Research Center 2016 report.

\section{Results}

First, I examined the percentage of participants who voted for the same versus different candidate in the 2016 presidential election. Results show that $79 \%$ of participants voted for the same candidate as their partner and $21 \%$ voted for a different candidate.

I hypothesized that ideology (i.e., higher numbers = more conservative) would predict lower odds of voting for a different candidate. I entered ideology into a binary logistic regression predicting whether the participant voted for the same candidate as their partner did $(0=\operatorname{Same}$ candidate, 1 = Different candidate $)$. Unexpectedly, ideology was not a significant predictor, $(b=$ $.02, S E=.04), p=.618, \mathrm{OR}=1.02,95 \% \mathrm{CI}[.94,1.11]$

As expected, however, the ideology $\times$ education interaction was significant, $(b=.11, S E$ $=.03), p<.001, \mathrm{OR}=1.11,95 \%$ CI $[1.05,1.18]$. I used the Johnson-Neyman technique from the PROCESS macro in SPSS (Hayes \& Matthes, 2009; Hayes, 2013) to identify the relationship between ideology and the dependent measure at every level of education. As expected, the effect was strongest at the lowest level of education. For participants with no high school degree, ideology significantly predicted whether participants voted for the same or a different candidate from their partner, $(b=-.35, S E=.11), p=.002, \mathrm{OR}=.70,95 \% \mathrm{CI}[.56, .88]$. That is, for every unit increase in conservatism, participants had 30\% lower odds of voting for a different candidate from their partner. As expected, this relationship got weaker the higher the participant's education. For example, the relationship between ideology and the dependent measure was also significantly negative for participants with some college education, but it was 
weaker, $(b=-.14, S E=.06), p=.020, \mathrm{OR}=.87,95 \% \mathrm{CI}[.77, .98]$. This relationship became non-significantly positive for participants with a college degree, $(b=.07, S E=.05), p=.166, \mathrm{OR}$ $=1.07,95 \%$ CI $[.97,1.18]$, but then, unexpectedly, became significant for participants with a postgraduate degree, $(b=.17, S E=.07), p=.011, \mathrm{OR}=1.19,95 \%$ CI $[1.04,1.36]$. For participants with a postgraduate degree, each unit increase in conservatism predicted 19\% higher odds of them voting for a different candidate from their partner.

Because education and income are correlated, $(r=.43, p<.001)$, and therefore income could confound the effect of education, I ran the same model as above with income entered as a covariate. The ideology $\times$ education interaction remained significant, $(b=.10, S E=.03), p=$ $.001, \mathrm{OR}=1.11,95 \% \mathrm{CI}[1.04,1.18]$, and the trends nearly identical (see Figure 1). Further, the trend and pattern of statistical significance was the same when also controlling for age and sex (see supplementary materials).

Figure 1. Proportion of participants who voted for a different candidate from their romantic partner in the 2016 United States presidential election as a function of ideology and education.

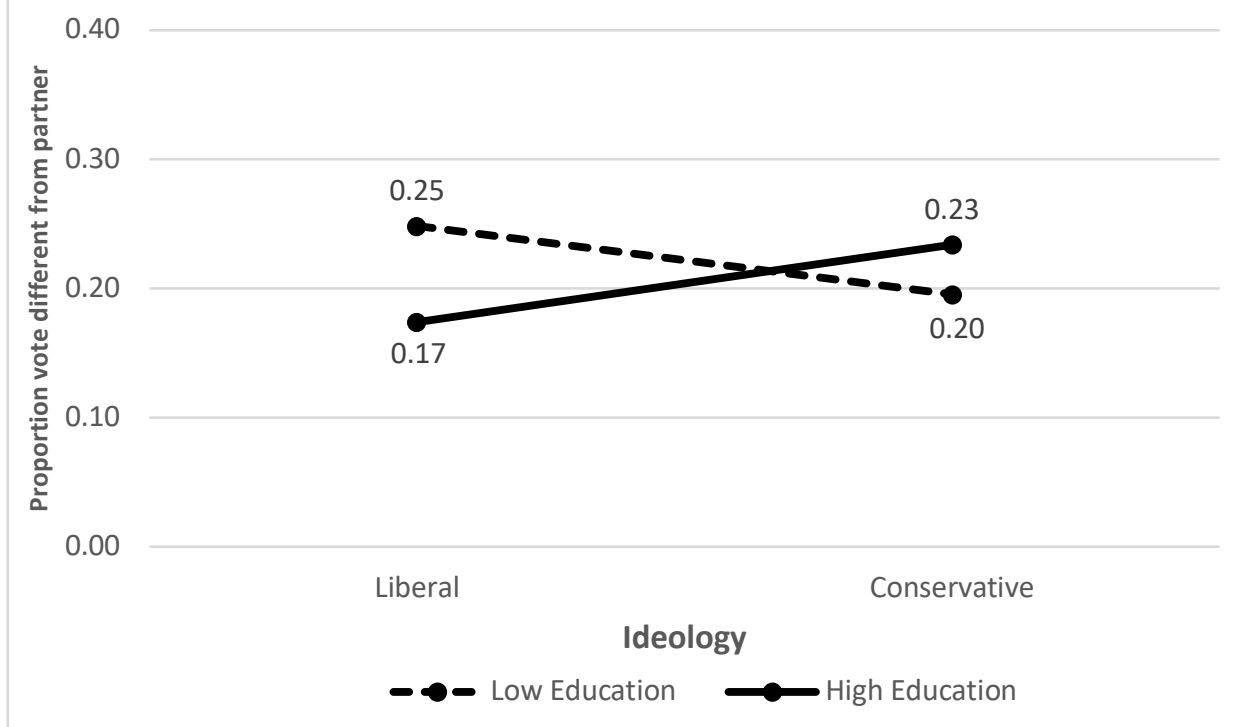

Note: Estimates adjusted for participants' income. Values for ideology and education are plotted at $-/+1$ standard deviation. 


\section{Discussion}

A growing literature shows that conservatives value loyalty and conformity more than liberals do (e.g., Goldberg et al., 2019; Jost et al., 2018). Additionally, recent research shows that, if desired, people resist conformity when they believe they are knowledgeable (Rios et al., 2018). The current study combined these concepts and tested them in a real world, highly contentious situation: the 2016 presidential election. The goal was to predict whether people are more likely to vote for the same or a different candidate from their romantic partner.

Although ideology alone did not predict whether people voted for the same or different candidate from their partner, I observed the expected interaction between ideology and education. That is, for those low on education, conservative participants were significantly more likely than liberal participants to vote for the same candidate as their partner. I hypothesized that this relationship would become weak or non-existent for participants higher on education. While this was true for moderate levels of education, higher levels of education unexpectedly turned this relationship positive-highly educated conservatives were more likely than highly educated liberals to vote for a different candidate from their partner. This pattern of results remained when controlling for income, age, and sex.

The absence of a relationship between ideology alone and couples' voting preferences raises additional questions. Although there is evidence that conservatives value loyalty and conformity more than liberals do, it is possible that a relationship with a romantic partner is powerful enough to make few people vote for a different candidate, regardless of their ideological position. Importantly, however, we extend upon previous research (Rios et al., 2018) to include political ideology and education as part of an informational influence process. That is, conservatives in conflict between their political convictions and their loyalty to their partner will 
yield to their partner when they are less able to justify their political beliefs but are more likely to stick with their political beliefs when they are more capable of justifying them.

Crucially, this study extends upon previous research in an area that has relied on samples from Amazon Mechanical Turk (MTurk; Stern et al., 2014; Rios et al., 2018). Because experiments on MTurk sometimes produce different results from experiments using representative samples (Krupnikov \& Levine, 2014) or other convenience samples (Goldberg, van der Linden, Ballew, Rosenthal, \& Leiserowitz, 2019), it is important for external validity that the current findings were observed in a nationally representative sample.

The primary limitation of this study is that it is limited to voting behavior. Further research should test whether the current pattern of results varies depending on whether the topic is relationship relevant, is personally important, or non-political. Although I made no causal claims, an additional limitation is that this study is correlational. While it is not feasible to manipulate the variables used in this study, lab experiments may use different topics in order to manipulate whether knowledge causes people to resist conformity when conforming conflicts with important ideological values.

With increasing polarization and partisan animosity in the United States (Pew Research Center, 2016a; 2016b), it is increasingly likely friends, family, and romantic partners will face strong disagreements with one another over politics. The current research sheds light on two factors (ideology and education) that influence whether people are likely to conform to the opinions of close others or resist doing so. This research will continue to be important as the political divide in the United States continues to shape public opinion and political behavior.

\section{References}


Aron, A., Aron, E. N., Tudor, M., \& Nelson, G. (1991). Close relationships as including other in the self. Journal of Personality and Social Psychology, 60(2), 241.

Asch, S. E. (1955). Opinions and social pressure. Scientific American, 193(5), 31-35.

Cialdini, R. B., Reno, R. R., \& Kallgren, C. A. (1990). A focus theory of normative conduct: recycling the concept of norms to reduce littering in public places. Journal of Personality and Social Psychology, 58(6), 1015-1026.

Caprara, G. V., Schwartz, S., Capanna, C., Vecchione, M., \& Barbaranelli, C. (2006). Personality and politics: Values, traits, and political choice. Political Psychology, 27(1), $1-28$.

Gearhart, S., \& Zhang, W. (2015). "Was it something I said?" "No, it was something you posted!" A study of the spiral of silence theory in social media contexts. Cyberpsychology, Behavior, and Social Networking, 18(4), 208-213.

Goldberg, M. H., van der Linden, S., Ballew, M. T., Rosenthal, S. A., \& Leiserowitz, A. (2019). Convenient but biased? The reliability of convenience samples in research about attitudes towards climate change. Preprint accessed at https://osf.io/2h7as/. doi.org/10.31219/osf.io/2h7as.

Goldberg, M. H., van der Linden, S., Leiserowitz, A., \& Maibach, E. (2019). Perceived social consensus can reduce ideological biases on climate change. Environment and Behavior, 1-23. doi.org/10.1177/0013916519853302.

Graham, J., Haidt, J., \& Nosek, B. A. (2009). Liberals and conservatives rely on different sets of moral foundations. Journal of Personality and Social Psychology, 96(5), 1029-1046.

Hardin, C. D., \& Conley, T. D. (2001). A relational approach to cognition: Shared experience and relationship affirmation in social cognition (pp. 3-17). In G. B. 
Moskowitz (Ed.), Cognitive social psychology: The Princeton symposium on the legacy arid future of social cognition. Mahwah, NJ: Erlbaum.

Hardin, C.D., \& Higgins, E. T. (1996). Shared reality: How social verification makes the subjective objective. In R. Sorrentino \& E. T. Higgins (Eds.), Handbook of motivation and cognition (Vol. 3, pp. 28-84). New York: Guilford Press.

Hayes, A. F. (2013). Introduction to mediation, moderation, and conditional process analysis: $A$ regression-based approach. New York: Guilford Press.

Hayes, A. F., \& Matthes, J. (2009). Computational procedures for probing interactions in OLS and logistic regression: SPSS and SAS implementations. Behavior Research Methods, 41, 924-936.

Jost, J.T., van der Linden, S., Panagopoulos, C., \& Hardin, C. D. (2018). Ideological asymmetries in conformity, desire for shared reality, and the spread of misinformation. Current Opinion in Psychology, 23, 77-83.

Jost, J.T. (2017). Ideological asymmetries and the essence of political psychology. Political Psychology, 38(2), 167-208.

Krupnikov, Y., \& Levine, A. S. (2014). Cross-sample comparisons and external validity. Journal of Experimental Political Science, 1(1), 59-80.

Mullinix, K. J., Leeper, T. J., Druckman, J. N., \& Freese, J. (2015). The generalizability of survey experiments. Journal of Experimental Political Science, 2(2), 109-138.

Noelle-Neumann, E. (1993). The spiral of silence: Public opinion, our social skin. University of Chicago Press.

Pew Research Center. (2016a). The Parties on the Eve of the 2016 Election: Two Coalitions, Moving Further Apart. Accessed November 3, 2018, http://www.people- 
press.org/2016/09/13/the-parties-on-the-eve-of-the-2016-election-two-coalitions-movingfurther-apart/.

Pew Research Center. (2016b). Partisanship and Political Animosity in 2016. Accessed November 3, 2018, http://www.people-press.org/2016/06/22/partisanship-and-politicalanimosity-in-2016/.

Pew Research Center. (2016c). Most Trump, Clinton Backers Say Spouses Share Their Vote Preferences. Accessed November 3, 2018, http://www.peoplepress.org/2016/10/18/most-trump-clinton-backers-say-spouses-share-their-votepreferences/.

Rios, K., Goldberg, M. H., \& Totton, R. R. (2018). An Informational Influence Perspective on (Non) conformity: Perceived Knowledgeability Increases Expression of Minority Opinions. Communication Research, 45(2), 241-260.

Sherif, M. (1936). The psychology of social norms. New York: Harper and Row.

Stern, C., West, T. V., Jost, J. T., \& Rule, N. O. (2014). “Ditto Heads” Do Conservatives Perceive Greater Consensus Within Their Ranks Than Liberals?. Personality and Social Psychology Bulletin, 40(9), 1162-1177. 